\title{
Interannual variability in the NCEP Reanalysis 1948-1999
}

\author{
Pedro Ribera ${ }^{1}$ and Michael E. Mann ${ }^{2}$ \\ Received 9 August 2001; revised 21 January 2002; accepted 12 March 2002; published 31 May 2002.
}

[1] We examine horizontally and vertically distributed climate fields in Northern Hemisphere NCEP reanalysis data (1948-1999) for joint modes of spatiotemporal variation. Our analysis is based on the "MTM-SVD" methodology to isolate significant spatially-coherent variability with narrowband, oscillatory character. Interannual tropospheric climate variability associated with the ENSO signal is identified in distinct quasibiennial $(2-3 \mathrm{yr})$ and quasiquadrennial (4-6 yr) frequency bands, with evidence of evolution in amplitude over time. From this dataset, there is no clear evidence to support the existence of any other significant oscillatory signal in the troposphere. INDEX TERMS: 3309 Meteorology and Atmospheric Dynamics: Climatology (1620); 3339 Meteorology and Atmospheric Dynamics: Ocean/atmosphere interactions (0312, 4504)

\section{Introduction}

[2] A large body of recent work has involved the application of multivariate frequency-domain analyses of 20th century surface atmospheric and oceanic climate fields in order to gain deeper insights into the spatiotemporal character of interannual and decadal climate variability [e.g. Barnett, 1991; Ghil and Vautard, 1991; Mann and Park, 1994; Mann and Park, 1996; Allen and Smith, 1994; Jiang et al., 1995; Moron et al., 1998; White and Cayan 1998; Park and Mann 2000; Tourre et al., 2001]. With more than 50 years of vertically-resolved observational climate fields available, it is now possible, albeit with some important caveats, to analyze the full three-dimensional spatiotemporal character of interannual and decadal climate variability during the latter half of the 20th century.

[3] Here, for such an analysis, we use the MultiTaper MethodSingular Value Decomposition ("MTM-SVD") methodology, discussed further below. This analysis builds on similar previous analyses of surface climate fields, providing additional physical insight into the underlying dynamical structure of interannual climate signals through examination of the relationship between multiple variables at multiple levels in the atmosphere during the typical evolution of a signal. Four different climate variables at two different levels (surface and mid-troposphere) are examined simultaneously. ENSO (E1 Niño-Southern oscillation) is identified as the only clear interannual climate signal at the hemispheric scale over the past 50 years. Its influence is shown to extend to through both vertical levels.

\section{Data and Methods}

[4] We made use of the NCEP reanalysis data [Kalnay et al., 1996] to characterize tropospheric variability in the Northern Hemisphere during the latter half of the 20th century (1948-

\footnotetext{
${ }^{1}$ Departamento de Fisica Aplicada, Universidad de Vigo, Ourense, Spain.

${ }^{2}$ Department of Environmental Sciences, University of Virginia, Charlottesville, VA, USA.
}

Copyright 2002 by the American Geophysical Union. 0094-8276/02/2001GL013905\$05.00
1999). Four different atmospheric variables at two different levels on a $5 \times 5$ degree latitude/longitude grid $(0$ to $85 \mathrm{~N})$ were used. These include air temperature, geopotential height, and zonal and meridional components of the wind at both near-surface (1000 $\mathrm{hPa})$ and mid-tropospheric $(500 \mathrm{hPa})$ levels. Monthly means from January 1948 through December 1999 were used, and the annual cycle was removed through forming monthly anomalies relative to a 1961-1990 base period for all variables and gridpoints used. All gridpoint anomaly series were normalized by their standard deviation to yield series with equal variance, and were weighted by a $\cos$ (latitude) areal representation factor prior to the analysis. The NCEP reanalysis is based on an intermittent data assimilation scheme performed with a T62 model with 28 vertical sigma levels and the Operational Statistical Interpolation (OSI) procedure for assimilation [Kalnay et al., 1996]. The data sources include rawinsonde profiles, surface marine reports from the Comprehensive Ocean-Atmosphere Data Set (COADS), aircraft observations, surface land synoptic reports, satellite soundings from the Tiros Operational Vertical Sounder (TOVS) and other platforms, surface wind speeds from the Special Sensor Microwave Imager (SSMI), and satellite cloud drift winds. Its extension back to 1948 can be followed in White [2000]. A discussion of potential limitations and biases in the data are described elsewhere in the literature [e.g. Hurrell and Trenberth, 1998].

[5] We apply the MTM-SVD signal detection method for identifying spatiotemporal signals in climate field data [Mann and Park, 1994; 1996; 1999; Mann et al., 1995; Rajagopalan et al., 1998; Delworth and Mann, 2000; Minobe, 2000; Tourre et al., $2001]$ to the 1948-1999 NCEP reanalysis data. The MTM-SVD approach identifies relatively narrow frequency bands in which there is significantly greater coherent variance in the data than would be expected under the null hypothesis of spatiotemporal colored noise [see e.g. Mann and Park, 1999, for a review]. Unlike standard EOF-based approaches [e.g. Wallace and Gutzler, 1981; Horel, 1981], the MTM-SVD method can identify spatially-evolving spatiotemporal signals by employing both phase and amplitude information in a multivariate frequency-domain analysis. A "Local Fractional Variance" ("LFV") spectrum identifies the dominant timescales of any statistically significant patterns of variability in the underlying climate fields. Once identified, the evolving spatial pattern of a typical cycle is readily reconstructed [Mann and Park, 1999].

\section{Analysis of NCEP Data}

[6] In Figure 1a, the LFV spectrum is presented for the 19481999 period based on MTM-SVD analysis employing 3 data tapers and a time-frequency bandwidth product of $\mathrm{w}=2 \mathrm{~N}$ [see Mann and Park, 1999]. Three potential signals are of interest. This includes a trend or multidecadal secular variation (associated with the peak near zero frequency that corresponds to timescales longer than half the analysis interval, or about 25 year period) which is significant at the $95 \%$ level, a broad peak between in roughly the $4-5$ year $(\mathrm{f}=$ 0.28 to $\mathrm{f}=0.2$ cycle/year) range significant at the $95 \%$ level, and a peak in the 2-3 year range significant near, but not quite at, the $90 \%$ level. Because this latter peak is significant at above the $90 \%$ level when we restrict the domain to lower latitudes, we interpret it as indicative of a real, but essentially tropical, signal. This subdivision of the interannual 3-7 year period ENSO signal into two 
a

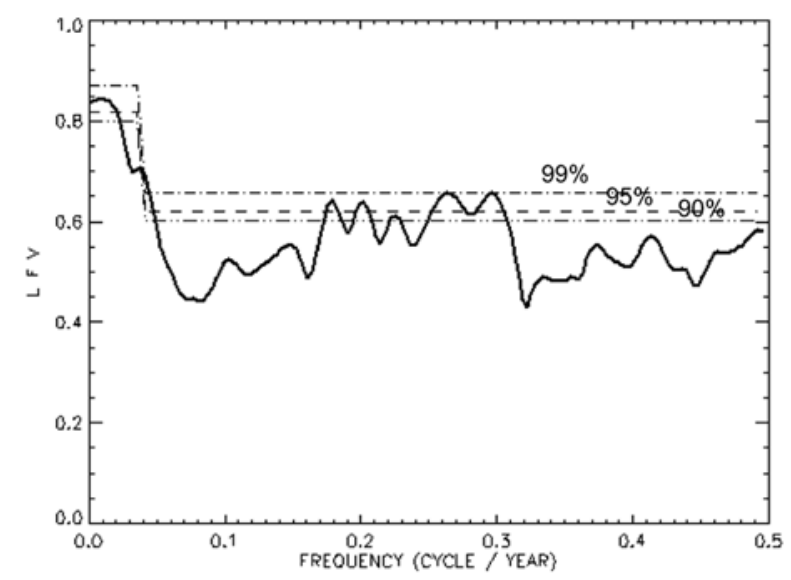

b

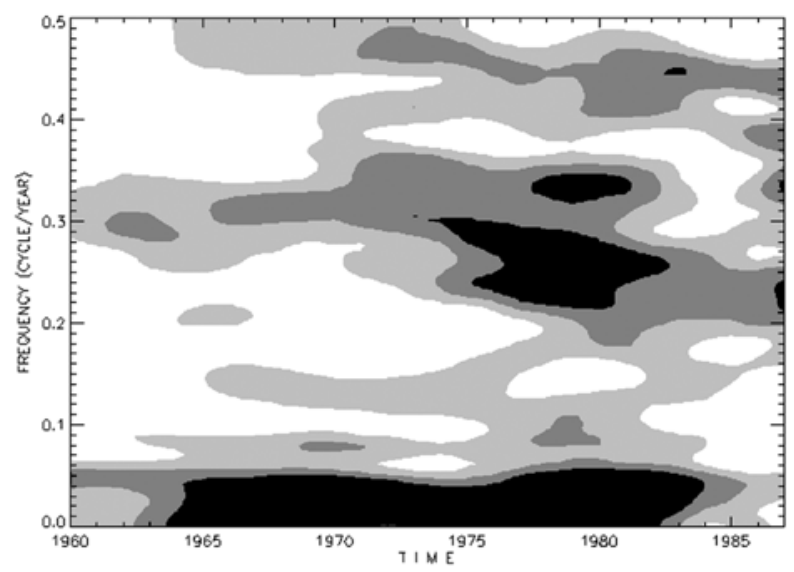

Figure 1. (a) LFV spectrum (1948-1999) with 90\%, 95\% and 99\% significance level. (b) Evolutive spectrum with a $25 \mathrm{yr}$ window. Significance is indicated by grayshading, color scale indicates $50 \%$ confidence level (light grey), $90 \%$ and $99 \%$ (black).

primary frequency bands, one centered at $2-3$ year period (quasibiennial or "QB", different from the "Stratospheric QBO") and the other at 4-6 year period (quasiquadrennial or "QQ") is supported by previous work [e.g., Barnett, 1991; Mann and Park, 1994; Jiang et al., 1995; Allan et al., 1996; Mann and Park, 1996; Allan, 2000]. There are multiple competing sources of multidecadal variability and trend during the 20th century [e.g., Mann and Park, 1994; Moron et al., 1998; Allan, 2000; Minobe, 2000; Tourre et al., 2001]. Moreover, sources of bias arising from changes over time in data assimilation in the NCEP reanalysis [Hurrell and Trenberth, 1998; Fiorino, 2000] preclude a reliable interpretation of long-term trends in the dataset. For these reasons, it is innappropriate to seek a detailed physical interpretation of the secular variation evident in this relatively short dataset.

[7] An evolutive MTM-SVD analysis [see Mann and Park, 1996; 1999] employing a 25 year window, was used to investigate the amplitude and frequency modulation of the interannual signals. The evolutive version of the LFV spectrum indicates two primary bands of variance corresponding to the QQ and QB bands identified above (ignoring the secular variance corresponding to timescales greater than about 12 year period with a 25 year window). These bands show notable changes in character over time, with the QQ peak drifting from about 3.5 to 4.5 year period over the 50 year interval, and the QB peak drifting from roughly 2 to 2.5 year period (and eventually reaching the $95 \%$ significance level) over the same interval. There is also evidence of a weak and intermittent 7-8 year period showing some relationship to the North Atlantic Oscillation or "NAO" [see e.g. Mann and park, 1994; Hurrell and Van Loon, 1997].

[8] The lack of a significant QB peak in the earlier part of the period studied is consistent with previous work that has argued for a weak amplitude of the QQ ENSO component between 1920 and 1960 [Kestin et al., 1998; Allan, 2000]. The interannual pattern of amplitude modulation shown in Figure 1 is also similar to a previous evolutive MTM-SVD analysis Northern Hemisphere (largely extratropical) surface temperature and SLP data [Mann and Park, 1996]. Park and Mann [2000] observed a similar interval of enhanced QQ ENSO-related variability during the 1970s and 1980s and a steady trend towards enhanced QQ variability in the late 20th century, based on a multivariate wavelet analysis of oscillatory "events" in the global surface temperature record.

[9] Figure 2 shows detailed spatial maps of the evolution of the QQ signal, following the evolution through one half cycle from peak warm event (maximum near-surface air temperature anomaly at the $0^{\circ} \mathrm{N}, 100^{\circ} \mathrm{W}$ gridpoint), through the development of cold-event ENSO conditions. The wind anomalies are consistent with expectations from the indicated geopotential height anomalies [ie, cyclonic convergence (divergence) about negative (positive) height anomalies at the near-surface $\mathrm{z}=1000 \mathrm{hPa}$ level, and essentially geostrophic winds at the mid-tropospheric $\mathrm{z}=500 \mathrm{hPa}$ level]. A complete animation of the signal evolution, can be found on the World Wide Web:http://holocene.evsc.virginia.edu/supplement/pribera The spatial patterns associated with both the QB and QQ signals display a classic ENSO structure. For example, the warm event phase of the pattern is associated with an anomalous negative surface geopotential gradient along the equatorial Pacific, a negative geopotential height anomaly extending up through the mid-troposphere along the Pacific coast of North and Central America, and the Northern Hemisphere half of the classic horseshoe pattern of warm and cold air temperature anomalies in the extratropical North Pacific. The patterns of surface temperature anomaly evolution associated with the QB (not shown) and QQ components are remarkably similar to those identified by Tourre [Tourre et al., 2001], with the QB band showing lower amplitude near-surface temperature variability that is more tightly confined to the equatorial region.

[10] Having established the connection between the QB and QQ signals in this study with the large-scale ENSO phenomenon, it is of interest to investigate connections with larger-scale patterns of climate variation. An examination of the evolving geopotential height anomaly pattern for the QQ pattern (Figure 2), for example, confirms the established close connection of the QQ band ENSO signal with the Pacific North American (PNA) pattern [Corte Real et al., 1996]. The signal evolution suggests a relationship between the PNA pattern and mass transport from low to mid-latitudes. We infer a pattern of mass transport from east to west along the eastern equatorial Pacific, from west to east at subtropical latitudes (approximately $20^{\circ} \mathrm{N}$ ), and with a subsequent split into two branches, one back towards the equatorial Pacific origin, and the other to the North, toward the Aleutian region. Such empirical inferences complement conclusions based on modeling studies [e.g. Lau and Nath, 1994].

[11] Also of interest are potential connections between ENSO and the South Asian Monsoon (SAM). In previous work, Terray [1995] and Khandekar [1997] detected QB and QQ band signals when studying the SAM, based on an analysis of monthly air temperature, SLP, SST and wind data, and argued for a connection with ENSO. This connection may extend the influence of ENSO into the extratropics; the SAM has a very important effect on the 
$1000 \mathrm{hPa}$
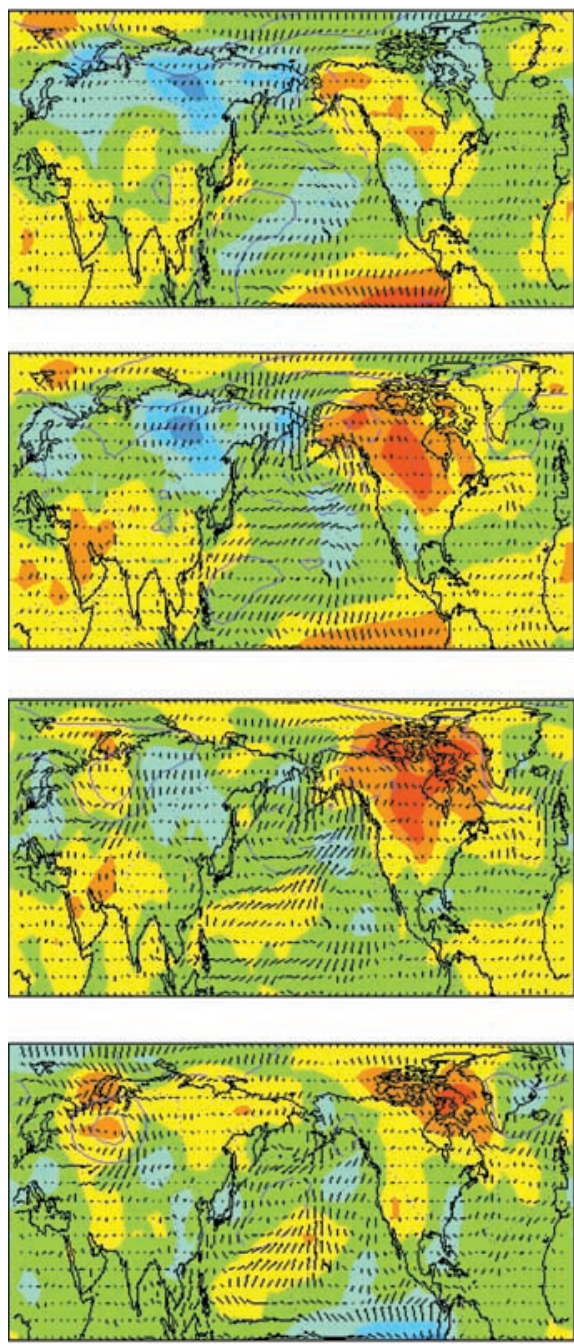

$500 \mathrm{hPa}$

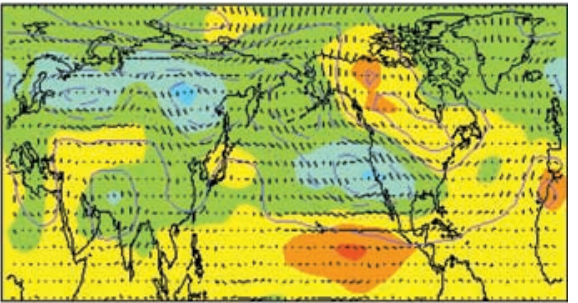

$45^{\circ}$

$1 / 2 \mathrm{yr}$

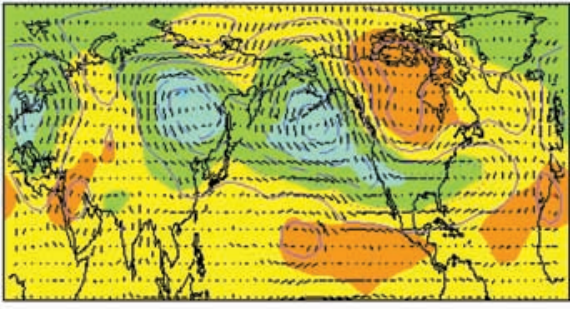

$90^{\circ}$

$1 \mathrm{yr}$

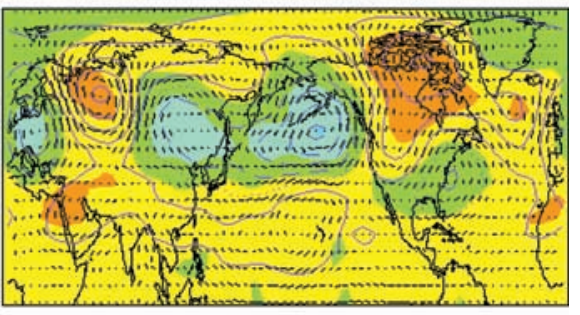

$135^{\circ}$

$3 / 2 \mathrm{yr}$

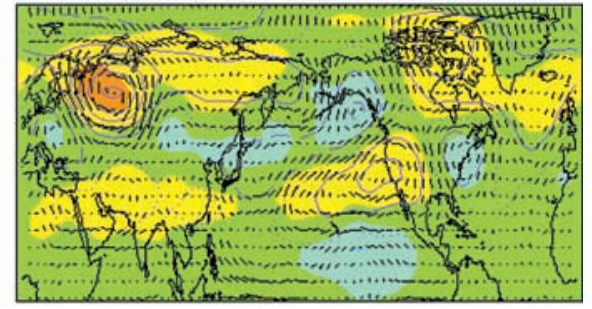

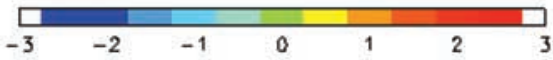

Figure 2. Spatial reconstructions of QQ oscillation (Phases $0^{\circ}, 45^{\circ}, 90^{\circ}$ and $135^{\circ}$ ). Temperature anomalies are indicated by the associated color scale. Geopotential height anomalies are indicated by (magenta) contours (solid line: positive anomalies, dashed line: negative anomalies, dotted line: zero contour, intervals shown indicate. .., $-16,-8$, $0,8,16, \ldots \mathrm{m}$ anomalies). Wind anomalies are indicated by vectors.

circulation regimes over South Asia, leading to an alternation between offshore and onshore flow over land regions, and a change in the transfer of mass and moisture. The QQ signal evolution indicates prominent geopotential and near-surface temperature anomalies not only over south Asia and Africa, but in more remote areas such as the eastern subtropical North Atlantic and parts of Western and Central Asia. It is possible that the apparent correlation between the SAM and Atlantic [Yasunary and Seki, 1992] simply arises from common linkages with the underlying ENSO signal.

\section{Conclusions}

[12] The only clear oscillatory interannual signal in tropospheric climate during the latter half of the 20th century is associated with the ENSO phenomenon, characterized by two distinct bands of variance, one with a dominant period of about $4-5$ years (QQ), the other with a dominant period of about $2-3$ years (QB). The QQ band signal is more prominent, and displays a more consistent character over time. The QB band signal only emerges as significant during the early 1960 s, slowly drifting from a dominant period of around 2 years to a dominant period of about 2.5 years by the end of the 20th century. The ENSO signal evolution established in this study confirms previously established connections (e.g. with the PNA pattern), but provides some further empirical insights into the pathways by which tropical anomalies may influence extratropical regions.

[13] Acknowledgments. We thank H. Diaz for his encouragement of this collaborative project. This work was supported by the International grant program of the Xunta de Galicia and by visiting scientist support from the University of Virginia (Department of Environmental Sciences). 


\section{References}

Allan, R. J., Lindesay, J. A., Parker, D. E., El Niño Southern Oscillation and Climatic Variability, 405 pp., CSIRO Publications, Melbourne, Australia, 1996.

Allan, R.J., ENSO and climatic variability in the last 150 years, Chapter 1, in El Niño and the Southern Oscillation: Multiscale variability, Global and Regional Impacts, edited by H. F. Diaz, and V. Markgraff, 3-56, Cambridge University Press, Cambridge, UK, 2000.

Allen, M. R., and L. A. Smith, Investigating the origins and significance of low-frequency modes of climate variability, Geophysical Research Letters, 21, 883-886, 1994

Barnett, T. P., The Interaction of Multiples Time Scales in the Tropical Climate System, Journal of Climate, 4, 269-285, 1991.

Corte-Real, J., X. Wang, and X. Zhang, Modes of variability in the Northern Hemisphere's mid tropospheric large-scale circulation, Theor. Appl. Climatol., 50, 133-146, 1996.

Delworth, T. L., and M. E. Mann, Observed and simulated multidecadal variability in the Northern Hemisphere, Climate Dynamics, 16, 661-676, 2000

Fiorino, M., The impact of the satellite observing system on low-frequency temperature variability in the ECMWF and NCEP reanalyses Proc. Of the Second WCRP International Conference on Reanalyses, 2000 .

Ghil, M., and R. Vautard, Interdecadal oscillations and the warming trend in global temperature time series, Nature, 350, 324-327, 1991.

Horel, J. D., A rotated principal component analysis of the interannual variability of the Northern Hemisphere $500 \mathrm{mb}$ Height field, Mon. Weather Rev., 109, 2080-2092, 1981.

Hurrell, J. W., and H. Van Loon, Decadal Variations in Climate Associated with the North Atlantic Oscillation, Climatic Change, 36, 301-326, 1997.

Hurrell, J. W., and K. E. Trenberth, Difficulties in Obtaining Reliable Temperature Trends: Reconciling the Surface and Satellite Microwave Sounding Unit Records, Journal of Climate, 11, 945-967, 1998

Jiang, N., J. D. Neelin, and M. Ghil, Quasi-quadrennial and quasi-biennial variability in the equatorial Pacific, Clim. Dyn., 12, 101-112, 1995.

Kalnay, E., The NCEP/NCAR 40-year reanalysis project, Bull. Amer. Meteor. Soc., 77, 437-471, 1996

Khandekar, M. L., Comments on Space-Time Structure of Monsoon Interannual Variability, J. Climate, 11, 3057-3059, 1997.

Kestin, T. S., D. J. Karoly, J. Yano, and N. A. Rayner, Time-frequency variability of ENSO and stochastic simulations, J. Climate, 11, 2258$2272,1998$.

Lau, N. C., and M. J. Nath, A Modeling Study of the Relative Roles of Tropical and Extratropical SST Anomalies in the Variability of the Globa Atmosphere-Ocean System, J. Climate, 7, 1184-1207, 1994.

Mann, M. E., and J. Park, Global-scale modes of surface temperature variability on interannual to century timescales, J. Geophys. Res., 99, D12, 1994.

Mann, M. E., and J. Park, Joint Spatio-Temporal Modes of Surface Temperature and Sea Level Pressure Variability in the Northern Hemisphere During the Last Century, J. Climate, 9, 2137-2162, 1996.

Mann, M. E., and J. Park, Oscillatory Spatiotemporal Signal Detection in Climate Studies: A Multiple-Taper Spectral Domain Approach, Advances in Geophysics, 41, 1-131, 1999.

Mann, M. E., J. Park, and R. S. Bradley, Global interdecadal and centuryscale climate oscillations during the past five centuries, Nature, 378 , 266-270, 1995

Minobe, S., Spatio-temporal structure of the pentadecadal variability over the North Pacific, Progress in Oceanography, 47, 381-408, 2000.

Moron, V., R. Vautard, and M. Ghil, Trends, interdecadal and interannual oscillations in global sea-surface temperature, Clim. Din., 14, 545-569, 1998.

Park, J., and M. E. Mann, Interannual Temperature Events and Shifts in Global Temperature: A Multiple Wavelet Correlation Approach, Earth Interactions, 4-001, 2000.

Rajagopalan, B., M. E. Mann, and U. Lall, A Multivariate FrequencyDomain Approach to Long-Lead Climatic Forecasting, Weather and Forecasting, 13, 58-74, 1998.

Terray, P., Space-Time Structure of Monsoon Interannual Variability, J. Climate, 8, 2595-2619, 1995.

Tourre, Y. M., R. Rajagopalan, Y. Kushnir, M. Barlow, and W. B. White, Patterns of Coherent Decadal and Interdecadal Climate Signals in the Pacific Basin during the 20th Century, Geophys. Res. Let., 28, 20692072, 2001.

Wallace, J. M., and D. S. Gutzler, Teleconnection in the geopotential height field during the Northern Hemisphere winter, Mon. Wea. Rev., 109, $784-$ $812,1981$.

White, G.H., Long-term trends in the NCEP/NCAR reanalysis. Proceedings of the Second WCRP International Conference on Reanalysis, pp. 54$57,2000$.

White, W. B., and D. R. Cayan, Quasi-Periodicity and Global Symmetries in Interdecadal Upper Ocean Temperature Variability, Journal of Geophysical Research, 103, 21,335-21,354, 1998

Yasunari, T., and Y. Seki, Role of the Asian Monsoon on the Interannual Variability of the global climate system, J. Meteor. Soc. Japan, 70, 177189,1992

P. Ribera, Campus As Lagoas, Universidad de Vigo, Ourense, 32003, Spain. (pribera@uvigo.es)

M. E. Mann, Department of Environmental Sciences, Clark Hall, University of Virginia, Charlottesville, VA 22903, USA. (mann@virginia. edu) 